\title{
41919
}

\section{Leveraging social media induced visual culture for body image enhancement: The case of socialization in a \\ contemporary society}

\author{
Delali Adjoa Dovie
}

\section{Resumo:}

Na contemporaneidade, há uma variedade de meios pelos quais o fenómeno da socialização é provocado. Um desses meios são as plataformas de media sociais. Mas beneficiar destes meios está dependente de dinâmicas intergeracionais tecnologicamente mais experientes. Este estudo de métodos mistos investiga a influência dos media sociais nas conotações culturais de socialização e aprimoramento da imagem corporal e como elas moldam mudanças nas aparências. Utilizaram-se dados da pesquisa [ $n=361$ ] para explorar a dinâmica dos media sociais em relação ao processo de socialização, enquanto os dados da entrevista [ $n=10]$ explicaram as questões levantadas no contexto do delineamento transversal do estudo. Análises bivariada e temática foram conduzidas respetivamente. Os resultados indicam que os resultados intergeracionais dos usos dos media sociais entre pessoas mais jovens e mais velhas são desviados em relação aos mais jovens e, portanto, o fosso geracional inerente verifica-se. $O$ valor do teste $C$ de 0,612 de Cramer sugere uma forte associação entre as imagens visuais dos media sociais e o tipo de aprimoramento da imagem corporal realizada. Isto tem implicações para a alfabetização tecnológica dos adultos ganenses mais velhos. A cultura do aprimoramento da imagem corporal é aprendida através da socialização induzida pelos media sociais em virtude da interação social orientada por estas plataformas. Dito de outro modo, esta forma de socialização desencadeia a disponibilidade, acessibilidade e exposição a certas imagens que precipitam uma necessidade desejada para a transformação de uma imagem corporal existente. Em geral, esta cultura é criada e transmitida de geração em geração. Este artigo oferece novas perspetivas sobre o fenómeno da socialização e o correspondente problema de mudança de estilo de vida, destacando o facto de que os efeitos das imagens dos media sociais no texto e nas imagens visuais são considerados formas de socialização. O resultado desta forma de socialização é o aperfeiçoamento da imagem corporal. 
Palavras-chave: media sociais; era digital; cultura visual; socialização; aperfeiçoamento da imagem corporal.

\begin{abstract}
:
In contemporary times, there are a variety of mediums through which the phenomenon of socialization is elicited. One of such means is social media platforms. But benefiting from this medium is dependent on the attribute of being technologically savvy intergenerational dynamics notwithstanding. This mixed methods study investigates the influence of social media on cultural connotations of socialization and body image enhancement, and how they shape changes in appearances. Use was made of survey [ $\mathrm{n}=361]$ data to explore social media dynamics in relation to the process of socialization, while the interview $[n=10]$ data explicated the issues raised in the frame of cross-sectional design. Bivariate and thematic analyzes were respectively conducted. The findings indicate that intergenerational outcomes of the uses of social media between younger and older people is skewed towards younger people and the inherent gap therefore pertains. The Cramer's V test value of .612 intimates a strong association between social media's visual images and the type of body image enhancement undertaken. This has implications for technological literacy among older Ghanaian adults. The culture of body image enhancement is learned and therefore has been learned through social media induced socialization by virtue of social media's oriented social interaction. Put differently, this form of socialization unleashes the availability, accessibility and exposure to certain images that precipitate a desired need for transformation of an existing body image. By and large, culture is created and transmitted from generation to generation. This paper offers newer insights into the phenomenon of socialization and the attendant lifestyle change nemesis, outlining the fact that the effects of social media imagery in both text and visual images is socialization. The outcome of this form of socialization is body image enhancement and/or transformation that yielded 'idealized bodies' aimed at acceptability in society.
\end{abstract}

Keywords: social media; digital age; visual culture; socialization; body image enhancement.

\title{
Introduction
}

Huisman and Kort (2019) write that these days, life without technology is unthinkable and more and more care organizations incorporate technology in daily care routines. In the same vein, Paulusson and Harder (2014) opine that images are becoming increasingly important in social media. They are observed in the success of networks such as Instagram, Pinterest or Snapchat, and of video networks like Facebook Live or Periscope featuring images. 
Most studies have based their visual corpus on extractions of images coming from social networks. Such studies expose methodological difficulties (Hochman \& Schwartz, 2012; Murthy, Gross \& McGarry, 2016) or search traces of a new visual culture, especially through selfies (Morin, Mercier \& Atlani-Duault, 2019; Tifentale \& Manovich, 2015; Walsh \& Baker, 2017), the art of exposing subjectivity (Zappavigna, 2016) or self-esteem enhancement (Hummel O'Donnel, 2016).

Images are a powerful vector of signification that social media users resort to extensively. Understanding text-image relationships is of great importance to grasping the full meaning of any message. Yet, it is unfortunately too common to read studies about social media platforms such as Twitter in which tweets are treated exclusively as text data or, more rarely, as platforms for sharing visuals. Many studies concentrate on social functions involving images such as the rise of 'citizen journalists' (Murthy, 2011), the documentation and management of life's catastrophes (Terpstra et al., 2012) and political crisis (Vis et al., 2013), or they limit themselves to analyzing how images contribute to the discursive construction of an event (Kharoub \& Bas, 2015; Seltzer et al., 2015).

Morin et al. (2019) note that the relationship between text and image is admittedly a very specific topic of research, however, it is essential to understand meanings on social media. Detaching texts from images or postulating the superiority of texts over images runs the risk of skewing research results.

\section{Theoretical underpinnings: McGregor's Theory $Y$}

McGregor's Theory $Y$ is the theoretical perspective that underpins this study. It shows that human behavior is based on satisfying a hierarchy of needs, namely physiological, safety, social, ego, and self-fulfillment (McGregor, 1960). Of these, social and ego needs are applicable in the context of this paper. Social needs refer to the desire for acceptance, affiliation, reciprocal friendships and love. Ego needs come in two distinct forms. The first form relates to one's self-esteem (e.g., it encompasses self-confidence, independence, achievement, competence, and knowledge). The second type deals with reputation, status, recognition, and respect from colleagues (McGregor, 1960) and/or significant others.

\section{Motivational factors}

The pursuance of body image alteration is usually motivated intrinsically and extrinsically. The intrinsic motivation dimension is the self-desire to seek out new things and new challenges, to analyze one's capacity, to observe and to gain knowledge (Ryan 
\& Deci, 2000a). It is driven by an interest or enjoyment in the task itself, and exists within the individual rather than relying on external pressures or a desire for consideration. Intrinsic motivation is a natural motivational tendency and is a critical element in cognitive, social, and physical development (Ryan \& Deci, 2000b). The two necessary elements for intrinsic motivation are self-determination and an increase in perceived competence. More often than not, individuals who undergo body image change may have an initial inward desire to do so. This may be complemented by outsider influence such as social media sources.

Extrinsic motivation is used to attain outcomes that a person would not get from intrinsic motivation (Ryan \& Deci, 2000a). Extrinsic motivations are rewards (e.g., satisfaction). However, there may be pain, or death. Competition is an extrinsic motivator because it encourages the performer to win and to beat others. Thus, most body image changers' purpose is to become unique or confident of their respective appearances.

\section{Issues of culture, social interaction and socialization}

According to Tylor (1871: 1, apud Dzorgbo, 2008: 79), culture is that complex whole which includes knowledge, belief, art, morals, laws, customs and any other capabilities and habits acquired by man as a member of society. Culture provides individuals with a set of common understanding that could be used to fashion their behaviors and actions (Dzorgbo, 2008). Culture is learned and shared by members of society. Culture has elements that are interrelated and constitute a complex whole. It is created and transmitted from generation to generation. As a result, it is historically derived.

Culture has three distinct layers that constitute learned behavior, pattern and perceptions. Layer one refers to shared language, traditions and beliefs that set each of different countries from each other. Layer two is pertains to identifiable subculture. The third layer relations to cultural universal. These are learned behavior patterns that are shared by all humanity collectively (O'Neil, 2006). Societal culture is normally governed by norms or rules which ensure the smooth, orderly functioning of the group. Chua (2002) writes that there is a relationship between the level of social interaction and the quality of knowledge created. Knowledge creation is constituted by socialization, externalization and combination. It also entails social interaction. The activities that engender knowledge creation necessitates social interaction. Social interaction occurs in different settings such as informal networks formed in organizations, within community practice, informal chats during social events, interpersonal relationships and everyday sense making activities among individuals, even in group settings (Chua, 2002; Dovie, 2019a, 2019b). Essentially, the level of social interaction positively influences the quality of knowledge created (Chua, 2002). There are three distinct dimensions of social interaction. These 
are structural, relational and cognitive dimensions (Nahapiet \& Ghoshal, 1998). The structural dimension to social interaction relates to the impersonal configuration of linkages between people or units. It influences the creation of knowledge via means which directly impact the conditions of accessibility to information and knowledge. For instance, when people are connected socially through physical means, namely being involved in brainstorming sessions, meetings and task forces or via electronic means as engaging in email, online discussions including social media platforms, the opportunity to access information and/or knowledge is enhanced. Inherent in the structural dimension is the presence or absence of social ties as well as network configurations that describe the patterns of linkages regarding measures namely density and connectivity (Nahapiet \& Ghoshal, 1998). Social ties provide access to resources and serve as valuable sources of information benefits. Information is important in providing a basis for action, but it is sometimes expensive to gather (Coleman, 1988 apud Chua, 2002). As network configuration properties, density and connectivity foster the flexibility and ease of the exchange of knowledge and/or information through their impact on the level of contact or accessibility thereof (Nahapiet \& Ghoshal, 1998).

Social interaction can here be defined as meaningful dialogue (Hurst, Wallace, \& Nixon, 2013) among individuals. Umberson and Montez cited "consistent and compelling evidence linking a low quantity or quality of social ties with a host of conditions" (2010: 2 ), including the development and worsening of cardiovascular diseases, repeat heart attacks, autoimmune disorders, high blood pressure, cancer and slowed wound healing. They pointed out that social interactions can enhance good health through a positive influence on people's living habits. Lack of social interaction also damages mental health. The emotional support provided by social connections helps to reduce the damaging effects of stress and can foster "a sense of meaning and purpose in life" (Park, Park \& Peterson, 2010: 6).

In her book entitled "The Happiness Track", Seppala (2016 apud Brody, 2017: 5) wrote, people who feel more connected to others have lower levels of anxiety and depression. Moreover, studies show they also have higher self-esteem, greater empathy for others, and are more trusting and cooperative and, as a consequence, others are more open to trusting and cooperating with them. In other words, social connectedness generates a positive feedback loop of social, emotional and physical well-being. However, a societal decline in social connectedness may help to explain recent increases in reports of loneliness, isolation and alienation, and may be why loneliness has become a leading reason people seek psychological counseling. A societal decline in social connectedness may help to explain recent increases in reports of loneliness, isolation and alienation, and may be why loneliness has become a leading reason people seek psychological 
counseling. By 2004, she wrote, sociological research revealed that more than 25 percent of Americans had no one to confide in (Brody, 2017). They lacked a close friend with whom they felt comfortable sharing a personal problem. It is also worthy of note that societal culture is normally governed by norms or rules which ensure the smooth, orderly functioning of the group.

The relational dimension to social interaction pertains to the kind of personal relationships developed by individuals through the pathway of interactions. It concentrates on the respect, friendship and the bond that people have built among themselves through particular relations (Nahapiet \& Ghoshal, 1998). This dimension comprises level of care, the norms of corporation among individuals as well as a sense of identification to a group (Putnam, 1995). It is worth noting that norms of corporation can institute a strong foundation for knowledge creation. Such norms influence social processes by opening up access to individuals in lieu of exchange and ensuring the motivation to engage in such an exchange. The cognitive dimension refers to social interaction among members of organizations including those resources providing shared representation, interpretations and systems of meaning among parties (Nahapiet \& Ghoshal, 1998). Shared language and codes, and shared narratives (Monteverde, 1995) are the core facets of this dimension.

Socialization describes the ways through which people interact with others to acquire knowledge, attitudes and behaviors essential for effective participation in society (Dzorgbo, 2008: 97). Socialization occurs throughout the life course because individuals need to learn new cultural norms, new occupations, and situations. For analytical purposes, socialization has been divided into at least five main phases, namely primary socialization, secondary socialization, re-socialization, anticipatory socialization and adult socialization. Primary socialization occurs in the family with parents and other close relations. It depicts training that takes place particularly in the family. The process of socialization occurs in all cultures and groups and begins within the family unit whereby one adopts the practices and beliefs of those around them. Secondary socialization usually occurs outside the family, in churches, schools, and at work. Re-socialization is the type of socialization that is said to have occurred when people are made to learn new patterns of behavior meant to replace older patterns of behavior they have. Anticipatory socialization entails individuals trying to copy the behavior and mannerisms of other people. Finally, adult socialization is said to occur when adults move to new neighborhoods, new occupations or new organizations (Dovie, 2017; Dzorgbo, 2008). It is associated with having to get acquainted with more dramatic changes in life or given situations such as retiring, losing a spouse, becoming disabled, preparing for death (Dzorgbo, 2008) (and adjusting to new conditions of life such as body image 
embellishments). Of these, secondary, anticipatory and adult forms of socialization are applicable in the context of this article.

Socialization is undertaken by agencies and agents. The agencies are the bigger units such as family, schools, churches/mosques, peer groups, the community and mass media. The agents are the individuals within these agencies, albeit parents in families, teachers in schools, pastors/imams in churches/mosques, peers in peers groups and the media organization (e.g. radio stations, newspapers, internet) (Dzorgbo, 2008) and a host of others).

The term professional socialization refers to the process by which one acquires specific knowledge, attitudes, beliefs and skills in order to be accepted as a member of a professional group (Parsons \& Griffith, 2007). The social media terrain is no exception. In other words, according to Curtis, Horton and Smith (2012) professional socialization is the process by which a person acquires the skills, knowledge and identity that are characteristic of a member of that profession and it involves an internalization of the values and norms of the group into the person's own behavior and self-conception (Cohen, 1981:14).

Socialization in compassionate practice involves combining exposure to learning from their personal lives, from professional theory, and from practiced experiences. Little alignment is experienced during their socialization from these different learning exposures and this dissonance results in feelings of vulnerability and uncertainty which may be managed through balancing between opposing intentions related to compassionate practice. Balancing is an internationally recognized strategy in coping with the day to day pressures (Hallin \& Danielson, 2007), and has emerged as the strategy used for coping with dissonance during socialization.

\section{Body image dynamics}

Body image is defined as a multidimensional self-attitude toward one's body, particularly its size, shape, and aesthetics (Holt \& Lyness, 2007). Sharifi, Omidi and Marzban (2016), Findler, Taubman-Ben-Ari and Jacob (2007) have observed that body image is how the human body is mentally perceived and has both perceptual and attitudinal components. Body image dissatisfaction is acknowledged as a pervasive problem experienced by a large proportion of society (Dohnt \& Tiggemann, 2006). These perceptions, thoughts, feelings, and behaviors can be positive or negative in nature and affect many aspects of psychosocial wellbeing and quality-of-life (Bailey et al., 2015).

The functional age of an individual may be determined by appearance - gray hair and wrinkles. But, in today's world, hair dye and face-lifts can alter appearances so 
dramatically that the normal signs of physical aging can be largely obscured (Quadagno, 2014). Body image is part of the self-state of one's physical appearance. Thus, individuals may experience negative emotional feelings when they perceive discrepancies between their ideal-body, ought-body, and actual body image (Kim \& Aubrey, 2015), a factor for a variety of unhealthy behaviors including fasting, self-induced vomiting, laxative misuse, and excessive exercise (Alleva et al., 2015). A historical perspective of the media's portrayal of the ideal body size and shape demonstrates change over the last century (Lawrie et al., 2006) and media exposure in individual's daily lives greatly demonstrate cultural values' appearance (Wagenbach, 2004). There is an increasing pressure in society in contemporary times for males and females to desire a body shape that conforms to the 'ideal', i.e. a 'shapey' body for women and a 'muscular shape' for men. These ideal body shapes are reinforced by the mass media including social media as well as popular cultural icons. Social media refers to "a group of internet-based applications that build on the ideological and technological foundations of Web 2.0, and that allow the creation and exchange of user-generated content" (Lee et al., 2014). The internalization of body ideals that are perpetuated by the media can be a strong influence on body dissatisfaction, especially among females (Hawkins et al., 2004; Sharp \& Tiggeman, 2016).

For a better understanding of the influence of social media on negative body image perception(s) and subsequent negative health behaviors (e.g., surgical removal and relocation), it is essential to examine how visuals generated by social media are associated with body image (Kim \& Aubrey, 2015) alterations. Decades of research has documented the negative impact that traditional media (such as magazines and television) has on people's body image concerns. Yet, given the increasing popularity of social media, the possible consequences that these new media formats have on body image (Fardouly \& Vartanian, 2016) have begun to be investigated. Images of idealized bodies and how individuals consume them has been extensively studied in terms of traditional media such as magazines, television, advertising among others. Little published research to date, however, has examined whether and how social media use, specifically, may influence perceptions of physical ideals (Andsager, 2014).

The main scope of this present work is to investigate social media utilization, information and visual access and body image concerns and contribute to the emerging literature on the relationship between social media and the cultural and body image transformations. It sought to address the following research questions: (1) what are the types of information obtained from social media sources? (2) to what extent does social media based socialization instigate body image enhancement and the associated consequences? 
The paper is organized as follows: section one introduces the study, section two presents the methodology employed in the study, section three presents study findings, section four discusses the findings and section five concludes the study.

\section{Materials and methods}

The research project began with some concerns and questions about social media culture and body image alterations in Ghana. The study used quantitative and qualitative datasets and a cross-sectional design to investigate the influence of social media on cultural connotations of socialization and body image depictions and how they shape the change in appearances. Use was made of survey data to explore social media dynamics in relation to the process of socialization, while the interview data explicated the issues raised.

\section{Site selection}

Accra and Tema were chosen because they depict the epitome of an urban setting. Also, they present a web of social relations, occupational diversity, a variety of activities as well as various events over time that provides richer and more interesting data (Ghanaweb, 2015), and suitability.

\section{Survey structure}

The survey structure comprises survey methodology, sampling of individual units from a population and associated techniques of survey data collection such as questionnaire construction and methods for improving the number and accuracy of survey responses. In other words, mode of questionnaire administration can have serious effects on data quality.

Face-to-face interview surveys have long been assumed to achieve higher response rates than postal and other types of surveys (Bowling, 2005). The face-to-face survey method was utilized in the study because of its propensity to produce data of high quality to a large extent barring item non-response. As the general concern of the study was to obtain a high response rate (96\%). However, the higher degree of satisficing among web respondents may lead to lower quality data than that obtained in the face-to-face survey (See Heerwegh \& Loosvelt, 2008 for details). Face-to-face survey allowed for non-verbal communication between the respondents and the researcher, which could motivate the respondents to properly respond to each of the questions (Holbrook, Green \& Krosnick, 2003). Face-to-face interviews are endowed with the merit of providing pertinent 
information while allowing the researcher the opportunity to control the line of questioning (Newman, 2004).

Responses to single-item global measures are found to be sensitive to small changes in survey question wordings, the order of survey questions, modes of administration, and other contextual factors not relevant to survey questions such as respondents' mood (Dolan \& Kavetsos, 2012). These bring to the fore the fact that there is a relationship between administration of questionnaire and validated responses.

\section{Sample selection and recruitment}

The study adopted the simple random sampling technique in selecting the respondents. This technique of sampling was used for two reasons. First, young people and older adults are a distinct group of study participants. Second, the study purports to identify particular types of cases for in-depth investigation (Newman, 2004). For the quantitative data, 361 younger individuals and older adults were selected. The sampling process entailed the random sampling of individuals aged 18-59 years (181) in the Tema Metropolis. People aged 60+ years (180) were selected using a list obtained from the National Pensioners' Association in Accra and Tema. The samples were selected from a total population of 364 and $700+$ respectively. The sample size was calculated using the following formula: $n=2(Z a+Z 1-\beta)^{2 \sigma 2} / \Delta^{2}$, with a power of $80 \%$ and a constant of 1.65 and a $p<0.05$ (Kadam \& Bhalerao, 2010). In the case of the qualitative data, 10 in-depth interviews were conducted with a section of participants. The sample for the qualitative phase was selected from that used in the quantitative phase, utilizing the purposive sampling technique. Purposive sampling was used for diverse reasons including its importance in the selection of participants who had specific characteristics such as sources of information.

Therefore, 361 questionnaires were given out, and were returned. Although the sample size was constrained by resources, 361 observations were selected as adequate for the study. The sample is large enough to help address the research questions accurately: (1) what are the types of information obtained from social media sources? (2) to what extent does social media based socialization instigate body image enhancement as well as consequences? The study also sought to explore the association between social media and influences in perceptions of body image among individuals. The usage of the simple random sampling technique means the results are statistically representative and to the general population. Thus, generalizability to the general population is permissible. 


\section{Research instruments}

\section{Questionnaire}

A questionnaire containing two sections was used in the process of data collection. Section one was on socio-demographic characteristics such as age, sex including educational level. The second section explored issues pertaining to social media, culture and body image concerns, measured with a 4-point verbalized scale from "extremely" to "not at all." The questionnaire was created based on previous research, input from colleagues and also the study's research interests. Examples of questions that have been previously used in published studies include questions about body image dissatisfaction acknowledgement (Dohnt \& Tiggemann, 2006). After the initial pool of questionnaire was written, qualified experts were made to review it, especially for grammatical corrections and accuracy. Before conducting a pilot of the questionnaire on the intended respondents, it was tested on a small sample of 30 individuals following the guidelines of (Perneger et al., 2015). Further, a pilot test among the intended respondents for initial validation was undertaken. All participants completed the same questionnaire.

Together, these were collectively contextualized to fit this study and the Ghanaian scenario. The survey questionnaire instrument's reliability was ensured in diverse ways, namely, facilitation by clear instructions and wording of questions. The questionnaire contained standardized instructions namely "please tick where appropriate". Also, trait sources of error were minimized through interviewing respondents at their convenience. The validity of the survey data was attained following Nardi's guidelines (2006). The validity of the data was obtained from face-to-face interviews. Also, the survey sought an alternative source for confirmation through further in-depth interviews. The face-to-face interviews were conducted in both English language and Ghanaian languages namely $\mathrm{Ga}$, Ewe, and Twi.

\section{Relationship between administration of questionnaire and validated responses}

The mode of questionnaire administration can have serious effects on data quality. Data quality could be defined in terms of survey response rates, questionnaire item response rates, the accuracy of responses, absence of bias, and completeness of the information obtained from respondents (Bowling, 2005). Yan et al., (2015) have purported that first of all, true values are needed to validate answers reported by survey respondents.

The method of survey administration in this study's context is personal in nature. Within different modes of questionnaire administration, there were many documented potential, 
biasing influences on the responses obtained. These were greatest between different types of mode (e.g. self-administered versus interview modes), rather than within modes (Bowling, 2005). The biasing effects of mode of questionnaire administration has important implications for research methodology, the validity of the results of research, and a host of others. There are likely to have different effects on the quality of the data collected. There are at least four steps involved in answering questionnaires, which make cognitive demands on respondents: comprehension of the question, recall of requested information from memory, evaluation of the link between the retrieved information and the question, and communication of the response.

Perhaps, the least burdensome method is the personal, face-to-face interview as this only requires the respondent to speak the same language in which the questions are asked, and to have basic verbal and listening skills. No reading skills are required.

The relationship between administered questionnaire and validated answers in this study was fostered by a linkage between the questionnaire design namely inputs from experienced researchers, piloting with experienced researchers and respondents. Further, sampling technique and methods were robust with the appropriate rationale and determination of sample size and the associated power. It is basically aimed at the minimization of measurement error, appropriate statistical procedures implemented from data collection to data validation, underpins quality statistics.

\section{Interviews}

The interviews were designed to gain an understanding of the influence of social media visuals on body image depictions and culture. The interviews lasted for approximately 45 minutes. Initially, the researcher reminded participants about the aims of the study. Each in-depth interview took the form of a semi-structured interview and was conducted individually in the participant's office or chosen place. The interviews were audio-taped. The 10 participants were divided into three planned interviews based on their convenience (i.e., participants' preference of time and location). Participants were excluded if they were younger than 18 years. The interviews were conducted in October 2018, approximately two months after completion of the questionnaire. The interview themes that emerged were related to the perception of body image, changes in body appearance, social media effects, and beauty.

\section{Ethical consideration}

Written informed consent was obtained from each research participant during the process of data collection. 


\section{Data Analysis}

Methodological triangulation was deployed to include the combination of methods to understand and explain (Greenstein, Roberts \& Sitas, 2003) the influence of social media utilization and socialization on body image enhancement. The answered questionnaire were cleaned and serialized for easy identification. The survey data were entered into Statistical Package for Social Science (SPSS) and were analyzed with selected descriptive statistics namely frequencies, percentages, and Cramer's $\mathrm{V}$ test.

Transcripts from the interviews were subjected to thematic analysis. Thematic analysis entails the process of encoding qualitative as well as textual information. Despite the strict procedural nature of coding and themes that emerge from constant immersion with qualitative data, Joffe and Yardley (2004) contend that thematic analysis is more exploratory. For the interviews, data analysis was first conducted by the researcher and subsequently by an independent researcher with experience in qualitative data analysis to increase confirmability and dependability. Both researchers ensured dependability by keeping a coding manual, which entailed original extracts from the interviews and definitions of the emergent themes (Johnstone, 2006). Inductive thematic analysis using NVivo10 software was undertaken (Bazaley \& Jackson, 2014). Each of the researchers read the scripts in detail, and then individually coded and categorized data from the same interview. Data from the interviews were coded by the researchers and across the entire interview data capturing diverse views. Through constant comparison, constant refining resulted in a list of themes (e.g., social media, socialization and influences in perceptions of body image among individuals) with their importance determined by frequency, multiplicity of participants' views as well as uniqueness.

\section{Results}

\section{Socio-Demographic Characteristics of Respondents}

The study population consisted of males (49.9\%) and females $(50.1 \%)$ aged $18+$ years (Table 1$)$. The majority of respondents $(58 \%)$ were married. The highest educational level attained by the majority of the respondents $(80.3 \%)$ was tertiary education constituted by first and second degrees. and post-graduate diploma. 


\begin{tabular}{|c|c|c|}
\hline Variables & Characteristics & Percent (\%) \\
\hline \multirow{5}{*}{ Age } & $18-29$ & 12.5 \\
\hline & $30-39$ & 12.5 \\
\hline & $40-49$ & 12.5 \\
\hline & $50-59$ & 12.6 \\
\hline & $60+$ & 49.9 \\
\hline \multirow[t]{2}{*}{ Sex } & Male & 49.9 \\
\hline & Female & 50.1 \\
\hline \multirow[t]{4}{*}{ Marital status } & Married & 58.0 \\
\hline & Divorced & 23.5 \\
\hline & Widowed & 7.5 \\
\hline & Single & 11.0 \\
\hline \multirow[t]{8}{*}{ Educational level } & Primary & 1.03 \\
\hline & JHS/MSLC & 5.6 \\
\hline & SHS/Tech/Com/Secretarial & 6.3 \\
\hline & GCE O' Level & 2.3 \\
\hline & GCE A Level & 4.5 \\
\hline & Bachelor's & 58.2 \\
\hline & Post-graduate diploma & 9.3 \\
\hline & Master's degrees & 12.8 \\
\hline
\end{tabular}

Table 1. Respondent demographics Source: Field data

It is worthy of note that the reference universe of the sample is significantly restricted to urban, educated people.

\section{Social media and information sourcing}

Social media is a platform that facilitates social networking including access to vital information. It is reminiscent of the domination of social media as a medium of information dissemination and access. Social media implies a huge opportunity to reach out to an audience and to increase information dissemination and access.

Platforms designated to Facebook, Instagram, Twitter, WhatsApp, Snapchat, Google, and a host of others denote what the study population utilized in accessing a myriad of information that transverse political, social and other dimensional issues in the Ghanaian society (Figure 1). As Figure 1 illustrates, comparatively more young people use and obtain diverse types of information from social media sources. In exception of WhatsApp platform that older adults registered a greater presence for (38.9\%), they could not compete with the younger generation with respect to the other platforms. This is suggestive of older adults' limited use of such media. This may be reminiscent of being technologically savvy, largely by the younger than older individuals. This is indicative of 
intergenerational gap in social media platforms usage. This has implications for intergenerational gap in social media access and utilization. It is worth noting that young people here mentioned refers to people aged 18-49 years, whilst older adults relates to people aged between 50-60+.

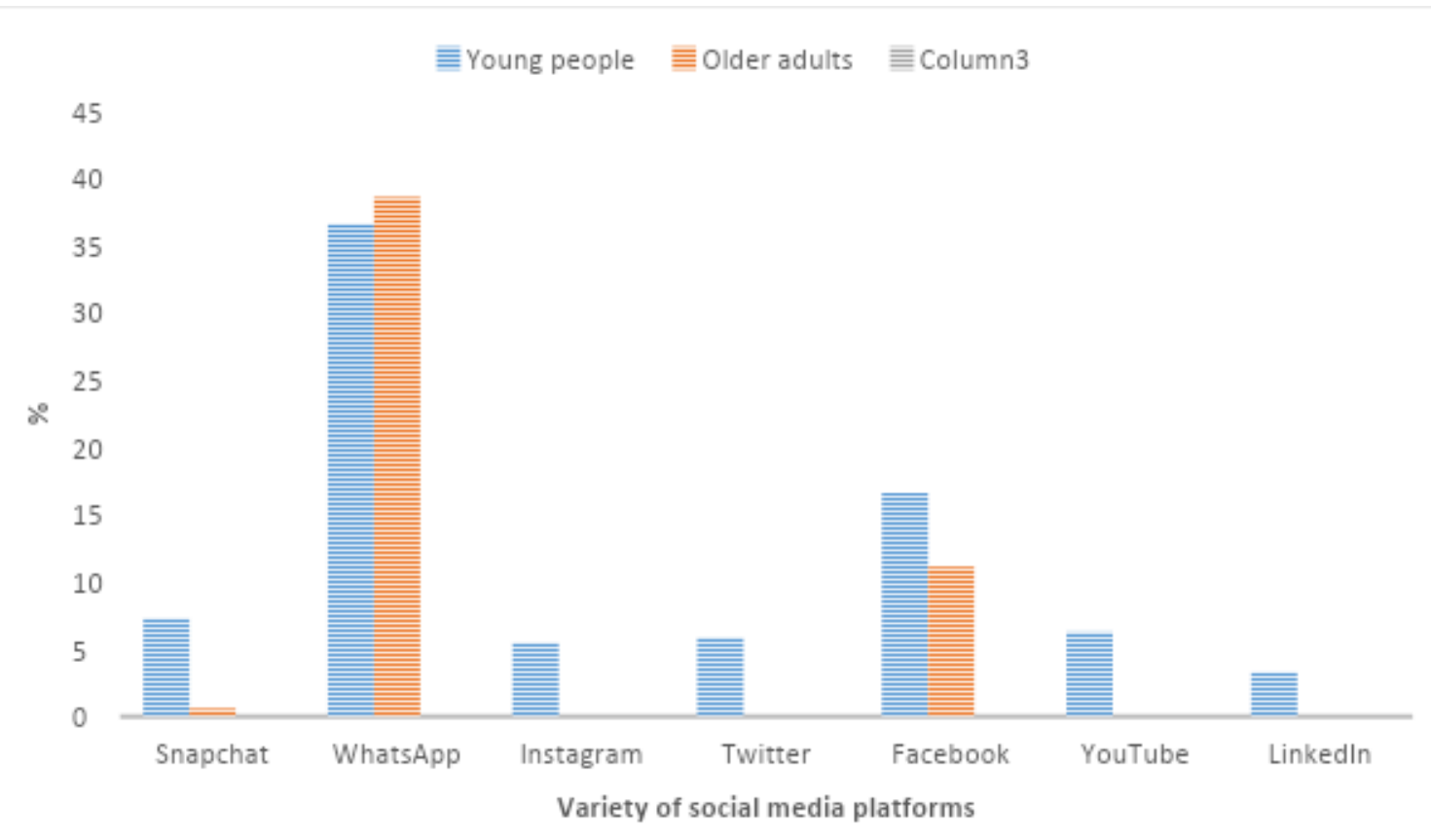

Figure 1. Social media platforms utilized

Source: Field data

The study participants used social media platforms for a variety of durations, ranging from multiple times per day (41.6\%) through to once a month $(8.9 \%)$ (Table 2), irrespective of the time of day in question.

\begin{tabular}{l|c|c}
\multicolumn{1}{c|}{ Duration of use } & Frequency & Percent (\%) \\
\hline Multiple times per day & 150 & 41.6 \\
Once per day & 50 & 13.9 \\
Every other day & 33 & 9.1 \\
Once in 3 days & 32 & 8.9 \\
Once per week & 32 & 8.9 \\
Once bi-weekly & 32 & 8.9 \\
Once per month & 32 & 8.9 \\
\hline Total & & $\mathbf{1 0 0 . 2}$
\end{tabular}

Table 2. Frequency of social media platform utilization Source: Field data

A myriad of methods are used to access social media platforms. Approximately, twothirds of the respondents use mobile app (65.7\%) to access social media platforms. In 
other words, mobile app is the most used method. The others are tablet app and computer web browser (Table 3).

\begin{tabular}{l|c|c}
\multicolumn{1}{c|}{ Duration of use } & Frequency & Percent (\%) \\
\hline Mobile app & 238 & 65.7 \\
Tablet app & 40 & 11.2 \\
Computer web browser & 63 & 17.5 \\
All modes & 20 & 5.8 \\
\multicolumn{1}{c|}{ Total } & $\mathbf{3 6 1}$ & $\mathbf{1 0 0 . 1}$
\end{tabular}

Table 3. Methods for accessing social media Source: Field data

The social media platforms mentioned above provide information related to education, business/investment, social, political, health and well-being, research, food and nutrition, entertainment, religion, current news/affairs, foreign news, events, shopping as well as weather/climate. Stated differently, social media sources of information are also a reflection of social media's propensity to socialize younger and older people educationally, politically, socially, financially, religiously, in terms of businesses and investment, events, weather, news of diverse forms, health and well-being as well as food and nutrition, which cut across a broad spectrum of human life dimensions.

On the one hand, males (8.5\%) dominate only in terms of obtaining political information from social media platforms. On the other hand, females comparatively dominated in accessed information on social $(8.0 \%)$, business or investment, food and nutrition, events as well as shopping. This is suggestive of the fact that females used social media frequently than males. This does not however relegate to the background the other dimensions of information articulated (See Table 4 for details). 
Table 4. Types of information obtained from social media sources

\begin{tabular}{l|c|c} 
Dimensions of information & Males & Females \\
\hline Education & $7.4 \%$ & $6.9 \%$ \\
Business/investment & $6.6 \%$ & $7.8 \%$ \\
Social & $6.3 \%$ & $8.0 \%$ \\
Political & $8.5 \%$ & $5.8 \%$ \\
Health \& well-being & $7.4 \%$ & $6.9 \%$ \\
Research & $7.4 \%$ & $6.9 \%$ \\
Food \& nutrition & $6.0 \%$ & $8.0 \%$ \\
Entertainment & $7.4 \%$ & $6.9 \%$ \\
Religion & $7.4 \%$ & $6.9 \%$ \\
Current news/affairs & $7.4 \%$ & $6.9 \%$ \\
Foreign news & $7.4 \%$ & $6.9 \%$ \\
Events & $6.6 \%$ & $7.8 \%$ \\
Shopping & $6.6 \%$ & $7.8 \%$ \\
Weather/climate & $7.4 \%$ & $6.9 \%$ \\
\hline \multicolumn{1}{c}{ Total } & & \\
\hline
\end{tabular}

Table 4. Frequency of social media platform utilization Source: Field data

The interview data corroborates the preceding intimations and outlines the dynamics of information sourced from Facebook, Instagram, Twitter as well as other related platforms. The interview data shows the following as the types of information obtained:

We learn a lot from social media, for example, news on the political front as well as other social issues (Female participant).

I obtain gospel, facilitated learning and reading abilities, current affairs, news, sports, entertainment and other development programs, social, and religious information through social media (Male participant).

I receive educative information, entertainment, politics, lots of interesting videos to entertain you and humorous content as well (Female participant).

We learn about other cultural issues across the globe, which has led to cultural diffusion and which has implications for our local culture, for example, the culture of body image change (Female participant). Social media helps in keeping in touch with family relations (Male participant).

We meet marriage partners visually through photographs obtained from social media. This has consequences for customary background checks of the couples that are conducted before marriages are contracted, which is weaved off. It is as a result of this that there are rampant divorce cases in Ghana in recent times (Male participant). 
Also, the facilitation of touching base with family relations denotes social interaction, a key component of social life that cannot be ignored. The last voice above articulates social media platforms' expansion of the marriage market in Ghana beyond funerals, lecture halls/schools, weddings and other social gatherings to encompass Facebook and a host of others. It also shows that the infiltration of social media into the marriage dimension of life adultrates the Ghanaian culture, customs and traditions in terms of background checks which is increasingly becoming non-existent, culminating into increased divorce cases. In the same vein, it adultrates original body image perceptions, depictions and sentiments, discussed in the next section.

\section{Social media and body image alteration}

Social media imagery provides information relating to the trimming of stomachs, facelifts, breast enlargements, hip enlargements, buttocks enlargements, penis enlargements and bleaching. The indication of social media platforms as sources of shopping for all manner of goods and services including garments, cars, fabrics, wardrobes, smartphones, including where to ascertain body image enhancement service providers shows that such platforms highly facilitate awareness raising at producers' images (81.8\%) and consumers' practices (63.6\%) (Figures 2). The main source of information that fosters body image enhancement is the social, food and nutrition dimension of social media information. Together, these facilitate body enhancements, especially breast, hip, buttocks and penis enlargements. Social information assists in service provision access including surgery, whereas food and nutritional information provide dietary needs and supplements required for successful outcomes. 


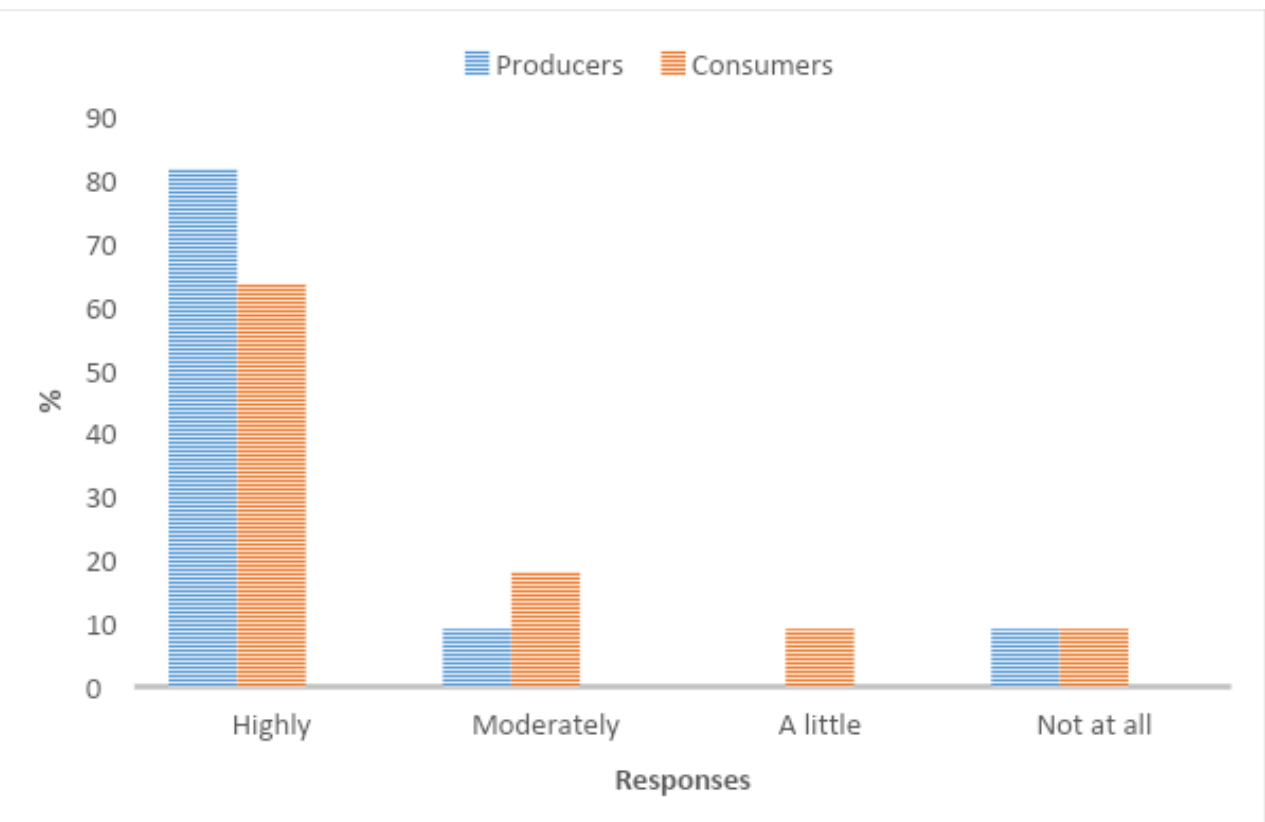

Figure 2. Social media facilitates producers' and consumers' practices Source: Field data

Consumers' practices here mentioned on one hand, may entail the patronage of cosmetic surgery of diverse forms. On the other hand, producers' practices involve the provision of such services as in cosmetic surgery clinics and/or facilities and surgeons as well as their respective paramedics including service providers, e.g. Obengfo Clinic in Accra as well as other facilitators and collaborators.

Majority of the individuals studied are of the view that social media influences perceptions of body image in contemporary times, age category notwithstanding (see Figure 3 below). Hence, more individuals in the $30-39,50-59$ and $60+(30.4 \%)$ age group largely alluded to this fact. This in turn implies that even the notion of body image transformation is an issue for young and old in spite of the form it may take. 


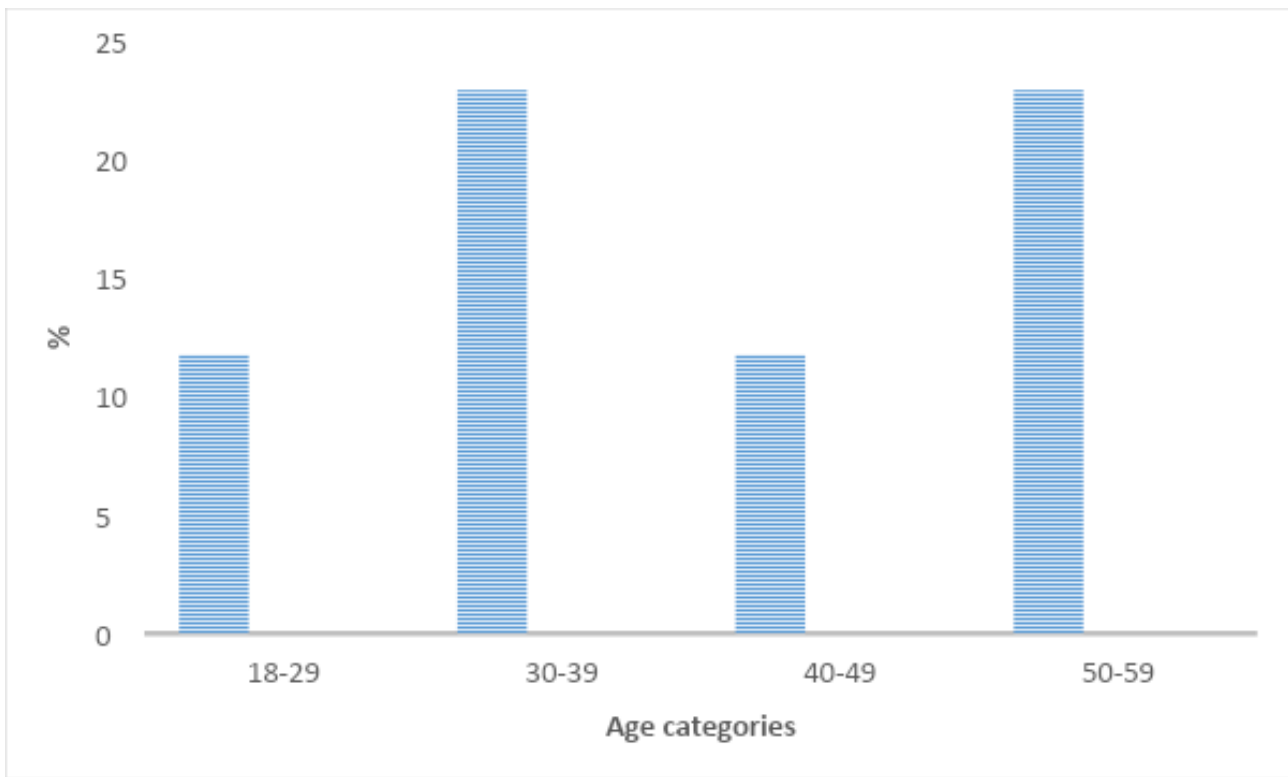

Figure 3. Perceptions of social media influences on body image Source: Field data

Social media has been projected as a tremendous life changer in terms of the visual images and texts it creates and disseminates, concerning life in general and body image enhancement in particular (Figure 4). The study respondents (58\%) expressed the fact that social media platforms are extreme life changers. In essence, social media sources provide information which otherwise may not have been easily accessible, particularly with respect to body image transformations.

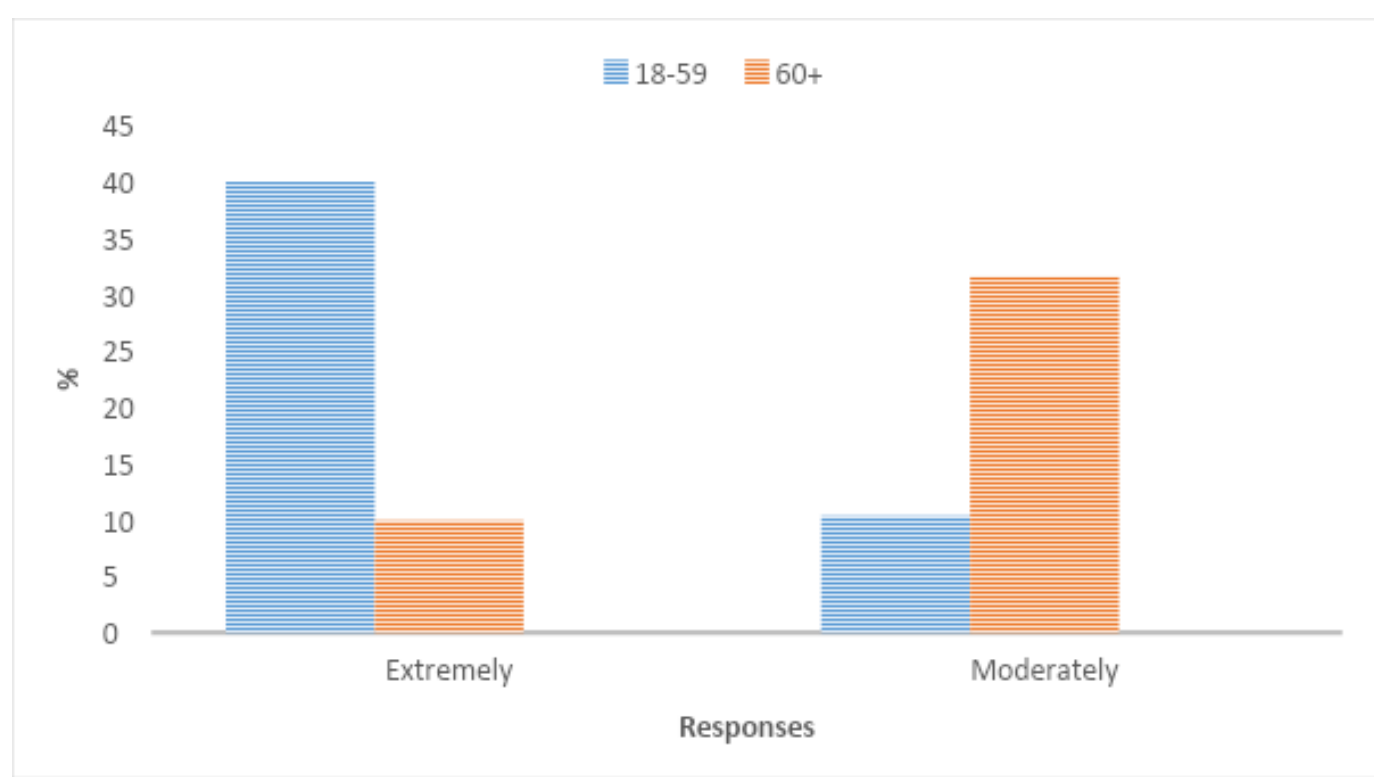

Figure 4. Extent to which social media transforms lives Source: Field data

Below is a compilation of some of the body image enhancement and/or transformation activities pursued on the basis of the visual images generated and obtained from social 
media platforms. These encompass beard growing, hair dyeing, face-lifts, breast enlargement, hip enlargement, buttocks enlargement, stomach trimming, and penis enlargement. As Figure 5 below depicts, breast, hip and buttocks enhancements are the most undertaken largely by females. These are all most pursued to look attractive to men and women on the social divide, with implications for social acceptance.

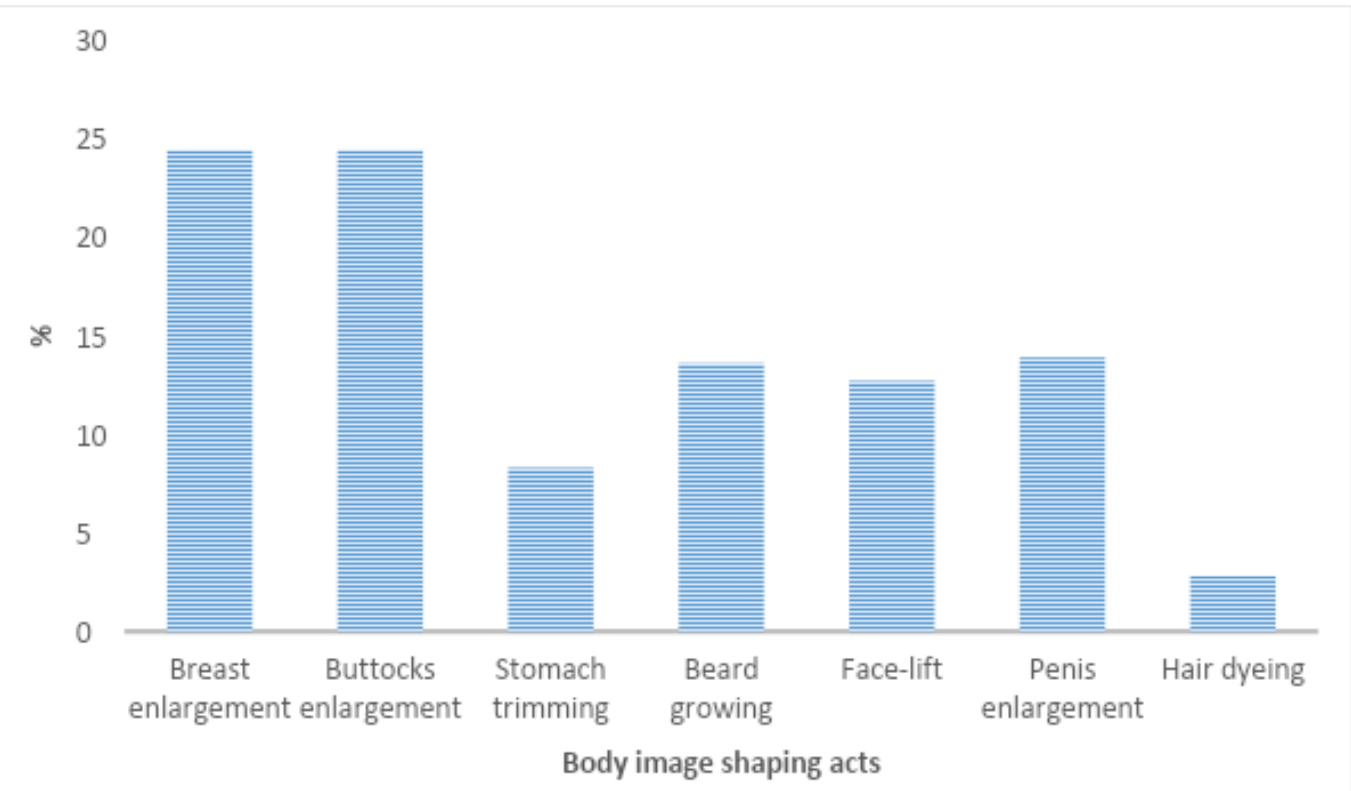

Figure 5. Social media information induced body enhancements undertaken Source: Field data

The interview data reveals in corroborating with the survey data that, both men and women seek to enhance their body images. It sought to explicate why people embark on body image embellishments. As a result, the following statements have been outlined:

Some men especially, those with small penis, seek to enlarge them (Female participant)

...the same way some of our women are suffering because they want big breasts, hips and buttocks (Female participant).

Whereas women seek to enlarge their breasts and buttocks, men seek to enlarge their penis just to be competitive and acceptable in society (Male participant).

The last statement above depicts the desire for social acceptance even in the cassock of a new image. 


\section{Consequences of body parts enlargements}

Body image transformations are intended to yield positive outcomes such as attractiveness to the opposite sex, a (potential) suitor or partner and social acceptance. However, the same when pursued have inherent side effects, some of which are more serious than others, including the otherwise waste of financial resources (34\%), excruciating pain and untimely death $(22 \%)$ of the pursuer in some cases (Figure 6 ). The excruciating pain dimension precipitates the adoption of other positions for a few weeks, a minimum 5 weeks, such as not sitting or lying on the buttocks for instance. Sometimes, the surgery involves the relocation of fat depositions, and if the rules are not strictly adhered to, there could be disfiguration of the part of the body redesigned.

These are mostly associated with face-lifts, breasts, hips, buttocks and penis enlargement and/or reduction in the size of penis. These leave the others namely beard growing or grooming and hair dyeing as less risky. But beard grooming in Ghana in recent times has attracted a reaction. Such that in obtaining a passport, any male who wears a bushy beard may be denied the passport if he refuse to cut it when prompted. This has become necessary because of terroristic tendencies in the world in contemporary times.

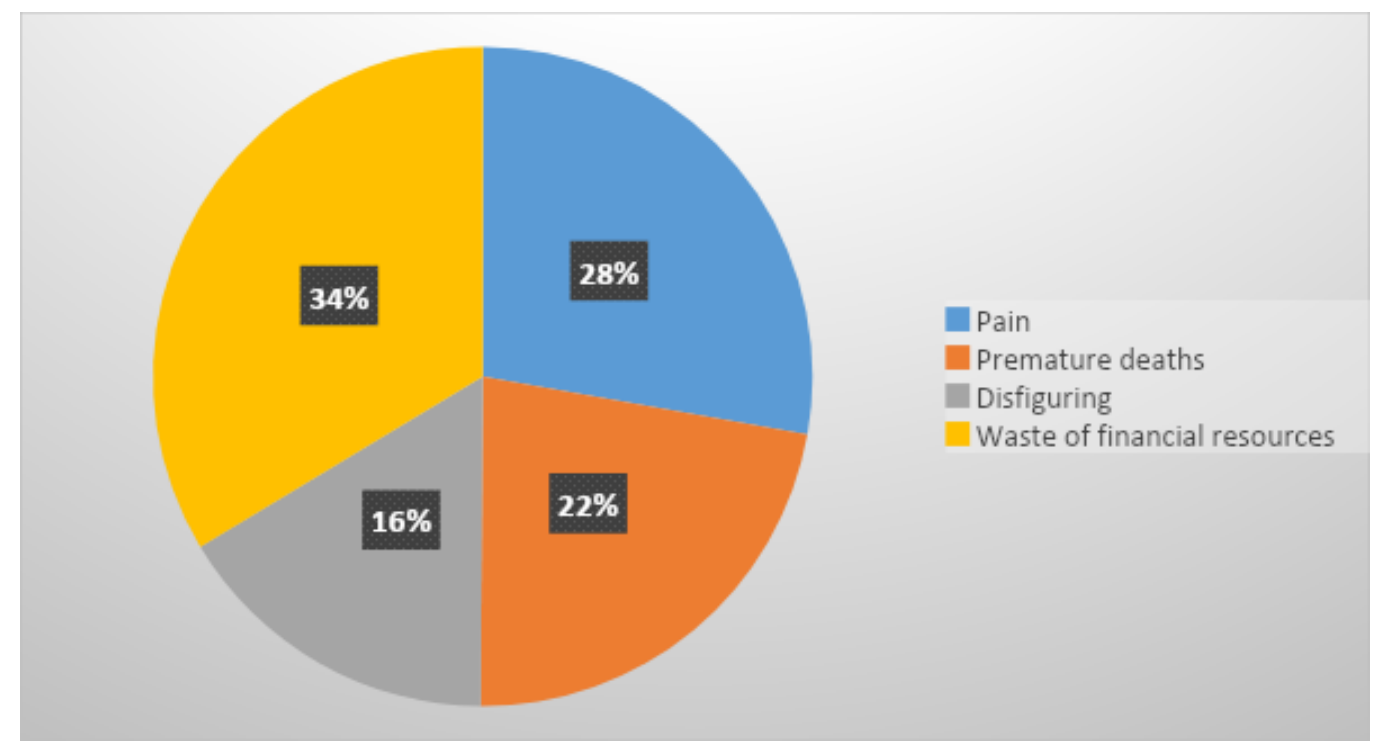

Figure 6. Some body enhancement challenges Source: Field data

There is a strong association between social media imagery and the type of body reshaping or enhancements executed and/or pursued by individuals. This is reflected by the Cramer's V Test value of .612 (See Table 5 for details). 


\begin{tabular}{l|c|c}
\multicolumn{1}{c|}{ Measures } & Value & Approx. Sig. \\
\hline Phi & .612 & .586 \\
Cramer's V Test & .612 & .586 \\
No. of cases & 361 & \\
\hline
\end{tabular}

Table 5. Association between social media imagery and the type of body reshaping pursued

Source: Field data

The sojourn of transformation in body image seems to be embarked on by both men and women. Although the components involved vary, the end product or result is practically the same - a new look as well as impression. It is worth reiterating the exploration of age as a factor to be taken into consideration when embarking on such sojourns with (biological) sex orientations in view. This implies that both men and women have issues and/or reservations with regard to some of their body parts, age and sex notwithstanding. For instance, according to The Sun (2019), 'billionaire diamond trader, 65 dies during penis enlargement surgery'.

Enlargement in selected body parts have implications for 'sexual appeal' men and women alike. The case of the billionaire may not be surprising because men in particular do not give up easily on sex. In consequence, the interview data observed that:

That is why even old men go in for young girls to remind themselves of their youthful sexual prowess, exploits and actions (Female participant).

\section{Social media sets the tone for cultural transformation}

Cultural transformation is usually fostered by a variety of factors. The results show that majority of the respondents (83\%) intimated that social media platforms also induce such transformations (Figure 7). 


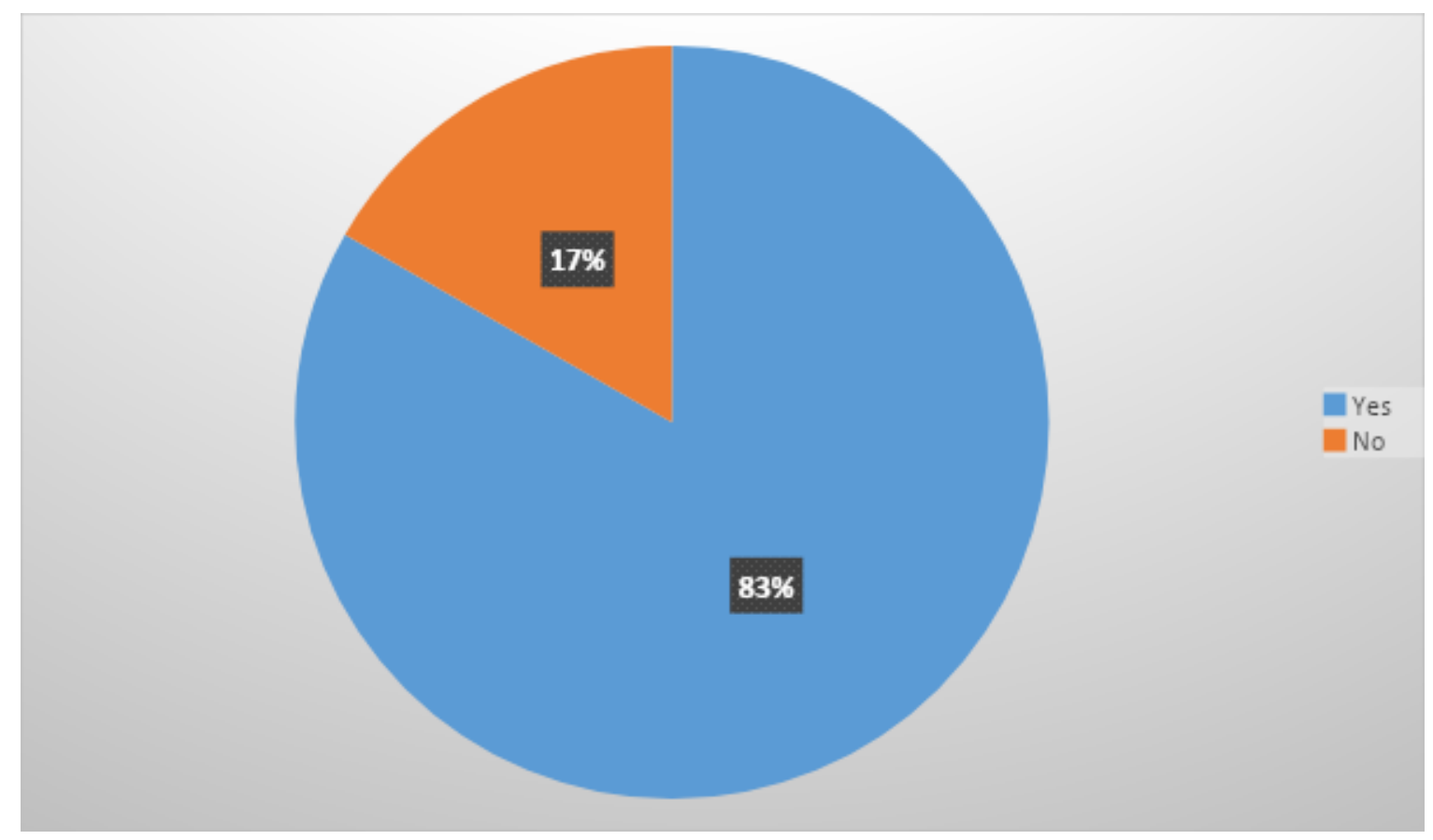

Figure 7. Depiction of the cultural transformation effects of social media Source: Field data

Similarly, the interview data expresses the notion that the information obtained from social media sources as earlier mentioned are usually a depiction of other cultures, not necessarily aligned to the 'receptive culture'. This is indicative of cultural diffusion, the reception of which results in embellishments in the existing culture. Although, this may seem like a new time for body part enlargement, it reminisces the notion of cultural universalism. Before the 'receptive culture' takes on elements of a new culture, it stands in the shades of cultural diversity since its specific to the Ghanaian context for example. The interview data reveals that culture is shared by all members of society. Culture then is dynamic, not static. Hence, it changes. The culture of body image enhancement is learned and therefore has been learned through social media induced socialization and is not biologically transmitted.

\section{Intergenerational dynamics and gap(s)}

Digital age and its visual culture favor generational barriers. As a result, comparatively only few older people who participated in this research are technologically savvy as mentioned in the section above, based on diverse media and digital competencies between generations (Figure 8). Stated differently, the visual culture generated by social media has become an approaching element for younger and older generations in the 
Ghanaian society. However, generation barriers are surmountable with the acquisition of information including that provided by social media platforms amid cultural expositions.

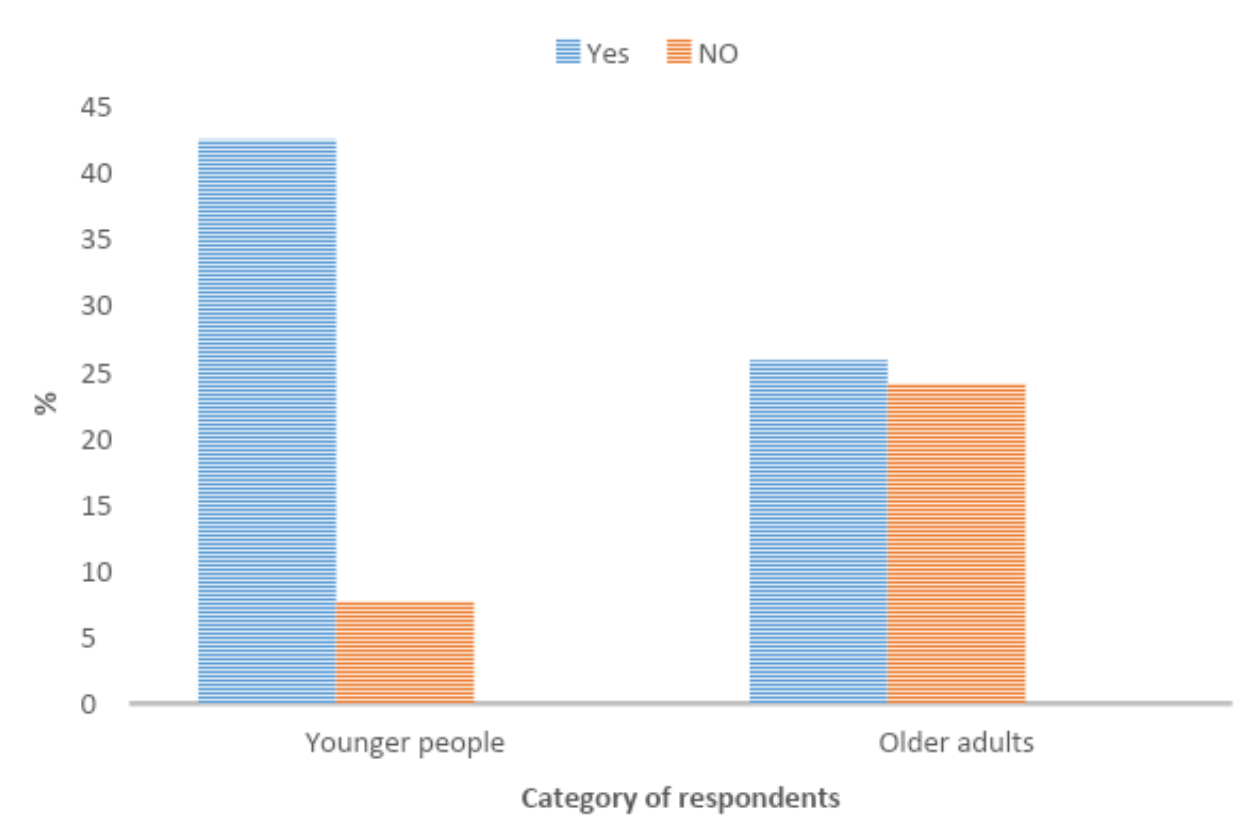

Figure 8. Articulation of perceptions on digital age and visual culture Source: Field data

The interview data profiles the fact that:

I believe that with the acquisition of knowledge, generational barriers can be broken (Female participant).

Social media facilitates exposure to cultures not previously known. Exposure to foreign culture is limitless with social media around (Male participant).

With the spread of information, the young and old generations are gradually forgetting their culture and basic ethnic traditions (Female participant).

\section{Discussion}

Generally, texts from social media platforms constitute a significant means of information for the patronizers of these platforms: concerning political, health, business or investment, entertainment (including sports), health, weather or climate, social, food and nutrition, learning or educational, and shopping issues. This in turn denotes information dissemination at diverse levels including visuals about trending body images, the notion of beauty and beauty therapies, locations and so on. This is therefore reflective of the concept of socialization. Interestingly, the results show that social media platforms were 
patronized for the duration ranging from multiple times per day, weekly, bi-weekly and monthly. In addition, they were accessed through mobile app, tablet app as well as computer web browser.

Culturally, social media platforms in essence facilitate the use of technological equipment for the transmission of information and/or ideas diversely. Such information was transmitted by both young and old. Information or ideas obtained from social media sources contributes to knowledge, which also is a core component of culture as articulated by Tylor (1871 apud Dzorgbo, 2008). In the same vein, adherence to social media platforms to obtain abundant information in turn induces enhancement in the capabilities or the experience of body image enhancement and the transformation thereof, culminating in understanding utilized to fashion the actions as (Dzorgbo, 2008) points out. Structurally, the existence of social ties among social media platform patronizers fosters access to resources including vital information. From a relational point of view, social interaction ensures knowledge creation via the availability of information for onward utilization. In the context of this study, culture is diversely learned by social media platform patrons and shared with society members. Men and women have the habit of changing their looks periodically. This therefore makes body image transformation a habit in the sense of culture.

Culture is a social heritage of a people, which is those learned patterns of thinking, feeling and acting and abstract creations such as ideas, norms, values, beliefs, symbols, customary practices, institutional arrangements including material artifacts namely houses, food, appearance and other technological equipment (e.g. smartphones, internet, computers) created by people and transmitted from generation to generation (Dzorgbo, 2008).

Social media platforms are vehicles for human interaction. The results reveal that a significant connection exists between the health and healthcare dimension inherent in the context of social media and social interaction, since social interaction on social media platforms elicit the ascertainment of health information. Hence, as Brody (2017) notes, social interaction is a critically important contributor to good health and longevity.

Social interaction improves or enhances knowledge or literacy, (critical thinking) and problem solving skills (Hurst et al., 2013). Social interaction is vital to the process of learning. In relation to knowing what can be done about a given situation or problem namely dissatisfaction with original/biological body image and resolving to alter it. Encouraging social interaction is one of the most effective ways to learn creative methods to solve complex problems (Darling-Hammond \& McLaughlin, 1995, apud Hurst et al., 2013). Inasmuch as social interaction is an everyday part of life in the real world, in the context of this article, it facilitates the transfer or sharing of vital information or 
ideas, that cut across a broad range of life's dimensions including body image enhancement targeted at social acceptance. It is via the process of social interaction that the process of socialization emerges. In short, social interaction brings to the fore socialization. In interacting, others serve as the agents of socialization (for details see Dovie, 2017, 2018a, 2018b). In a study conducted on the impact of social interaction, Hurst et al. found that social interaction enhances critical thinking, expanded comprehension of retention by activating knowledge, making connections and consolidating new ideas (2013: 386). This may allude to the fact that "it [social interaction] made [people] think in different ways" (Hurst et al., 2013). In essence, through social media platforms: "conversation helps individuals make sense of their world. It helps to build empathy, understanding, respect for different opinions and ownership of the learning process" (Ketch, 2005). Social interaction is important ... because it gets [people] to communicate with each other" (Hurst et al., 2013: 391). As a result, Page (2010) suggests that learning is individualized, constructed, interactive, emotional and social.

From a cultural viewpoint, socialization is undertaken by agencies such as family, peers groups, schools, churches/mosques, including the mass media. Correspondingly, the agents of socialization encompass parents and family relations, peers, pastors/imams, teachers, print and electronic media, among others. Social media platforms then serve as the agency of socialization and the individual patronize are agents of socialization. Socialization in the context of this paper may be different from professional socialization as articulated by Curtis et al. (2002) and Parsons and Griffith (2007). However, it may be a contributor to the attributes of professional socialization. The process of socialization has led to a lack of autonomy, self-reflection and authority to question practice. Further, attributed to aspects inherent in the socialization process are obedience to authority as well as conformity for acceptance (Parsons \& Griffiths, 2007).

\section{Connection between social media influence and maintenance of social ties}

Quick access to information and social inclusion were reported as some of the respondents appreciated the quick access to information on social media mediums on the go. In addition, although not exclusive to social media patronage, participants enjoyed the social interaction it facilitated. Yet, contrarily, as people get older and retire, they may miss out on important opportunities for social interaction (Findlay, 2003). Social media platforms offer a social interaction opportunity for people across varied economic 
or social backgrounds and age categories. In so doing, it generates positive effects such as confidence in body image and/or appearance.

Participation on social media platforms has the propensity to foster satisfying relationships with family, friends and community members, and facilitate healthy living and healthy lives. This has implications for fostering and consolidating strong social ties and in consequence social connectedness. It is in the light of this that the Harvard Women's Health Watch (cited in Brody, 2017) reported that 'dozens of studies have shown that people who have satisfying relationships with family, friends and their communities are happier, have fewer health problems and live longer'.

Keeping in touch with family was one benefit of social media utilization that the study participants noted. This is in line with previous findings. For example, an American Association of Retired Persons [AARP] (2017) survey reported that about $90 \%$ of adults over 50 years old use technology to stay connected to family and friends (i.e., $91 \% 50$ 59 years, 92\% 60-69 years, 88\% over 70 years). Yet, with the focus of today directed more at technology and the digitization of this era, it is easy to feel lost or left behind, especially if one falls within the aged category. This is because most technology is not as age-friendly with all the complex designs and operations as anticipated. However, the advantage of the rapidly progressive advancements in technology is that the aging process can be enhanced through the creation of assistive technology designed specifically for aging and the aged. Klimova, Simonova, Poulova, Truhlarova and Kuca (2016) suggested that older people use technologies at a basic level, and are quite inefficient at more complex tasks including financial transactions.

\section{Motivation and social media imagery}

Motivation is derived from the word motive which is defined as a need (e.g., body image dissatisfaction) that requires satisfaction. These needs could also be wants or desires that are acquired through the influence of culture, society, lifestyle, social media, among others. An individual's motivation may be extrinsically inspired by others or events (Ryan \& Edward, 2000a) influence of social media imagery or it may come from within the individual (Ryan \& Edward, 2000b). In the context of this paper, social media induced imagery is reflective of the extrinsic motivator to undertake body image enhancement. Motivation has been considered as one of the most important reasons that inspire a person to act (Jodai, Zafarghandi \& Tous, 2013) in a particular way. This may be as a result of their increased exposure to social media, allowing them opportunities to more accurately determine the ease of use and potential utility. This corroborates the findings of TAM (Davis, Bagozzi \& Warshaw, 1989), who noted that individuals tend to adopt pieces of technology if they are useful and easy to use. The study found that two factors 
explained the overall sample's responses: usage of social media platforms and also its provision of visual cultures and/or images in relation to others' experiences and, looks and the bid to look same as well as usefulness appears to form a single factor in this paper. From for instance, the visual images posted on social media platforms namely YouTube, WhatsApp, Twitter, Instagram, Facebook and a host of others. Further, individuals' motivation to change their appearances may also appreciate its usefulness. Some cultural issues are related to traditions, religious beliefs, representations of health and disease, life and death, sexual norms and practices. Culturally, body image enhancement is a belief that anticipates acceptance from society at large.

\section{Body image, socialization and culture}

The self represents the ideas individuals have regarding their attributes, capacities, ways of thinking, style of dressing, color preferences, desires, values, wishes, behaviors and body images. These conceptions make individuals think that they are special, unique and different from others. The self is developed through socialization induced by social media images and visuals. And it is in this regard that those who have faulty or incomplete socialization are perceived as lacking stable self-conception. Hughes and Kroehlor (2005: 82) note that "the formation of the self - the set of concepts we use in defining who we are is a central part of the socialization process". This self is not logically given but developed in the process of interaction. In other words, through social media, Leslie, Larson and Gorman (1973) argue that individuals learn via socialization to take account of social order and to cope with it by conforming to social media related images. Social media platforms are sources of vital information making accessible, visuals and texts. The visuals contain information related to images. Some of these visual images induce the intergenerational desire and the need to transform body images from an older to a newer one. This finding is consistent with that of Morin et al. (2019), who in a study on 'text-image relationships in tweets: shaping the meanings of an epidemic' argued that the research proposes a four-category classification of text-image relationships. Theoretically, it provides original insights into how discourses are built in social media; it also highlights the semiotic significance of images in expressing an opinion or an emotion.

The results suggest that positive changes in people's attitudes are possible with appropriate guidance and support. These changes were gradual and required time. Also, Vogel et al. (2014) found that social media visuals improved participants' perceptions about using social media. Despite the positive effects on participants' overall confidence, some participants mentioned that they did not feel confident enough. 
Those who pursue face-lifts to look younger while getting get rid of wrinkles may be said to have undergone anticipatory and adult socialization, since by this medium they expect to look younger even in older bodies. They also experience adult socialization because looking younger denotes a new dimension to life that they have to get acquainted with. At the same time, body image enhancement is endeared by secondary socialization as social media platforms fall within that frame of reference.

In recent times, dissatisfaction with one's body shape is ameliorated utilizing social media imagery of a better or a preferred body shape, ascertained through the requisite information obtained via mediums such as WhatsApp, Instagram, YouTube, Facebook and Twitter. It is on the basis of these that breasts, hips, buttocks and penis enlargements including others are pursued. Body image enhancement is tantamount to self-esteem enhancement, which is consistent with Hummel O'Donnel's (2016) findings. It is also a confirmation of McGregor's Theory $Y$ postulation in relation to self-esteem, precisely the self-confidence aspect of it. Yet, such results come with challenges namely pain, disfigurement and death.

Body image transformation in this context may be likened to Erving Goffman's (1981) impression management in terms of how people influence the perceptions others have about them. Also, the enhancement influences people's perceptions of the self, involved. Therefore, as Goffman writes, the social world constitutes a stage on which individuals interact. People in interaction are like actors in the theater performing for their audiences. During social interaction, individuals try to present themselves in favorable light as depicted in social media imagery and the antecedent body image enhancement. Most people want other people to have favorable impressions about them. They do this through a variety of ways: dressing, speech style, make up, hair styles, intonations, gestures, including body image embellishments.

Personal resilience is required to positively adjust and thrive in difficult environments (Jackson, Firtko \& Edenborough, 2007), where constraints in order to uphold their ideals need to be challenged. The development of resilience depends on working within caring environments and teams. People struggle to make sense of the dissonance between ideals and reality. Similarly, personal disappointment can arise if expectations are overambitious and out of alignment with reality.

\section{Conclusion}

This paper offers newer insights into the phenomenon of social interaction and the associated socialization, body image transformation and nemesis. Comparatively, the most used social media platform by older adults is WhatsApp, whereas the younger generation patronizes a wider range of such platforms - Twitter, YouTube, Snapchat, 
Instagram, Linkedln. This is suggestive of the older generation's limited use of such media platforms. It brings to the fore a generational gap in the extensive utilization of social media platforms. Technological literacy programs are recommended for older Ghanaian adults. In furtherance to this, these platforms were mostly accessed via mobile app, tablet app and computer web browser. The platforms were however accessed multiple times per day, weekly, bi-weekly and monthly. In addition, they were accessed through mobile app, tablet app as well as computer web browser.

Social media platform patrons learn culture, which is shared with members of society. The availability of a diversity of information on social media platforms namely political, health, business or investment, entertainment (including sports), health, weather or climate, social, food and nutrition, learning or educational, shopping issues, make social media platforms an empowerment tool for crucial decision making in all spectrums of life. Body image enhancement is reminiscent of innovation in the form of newer body part versions, quite apart from new creations in that regard.

The effects of social media imagery in both text and visual images is socialization. The outcome of this form of socialization is body image enhancement that yield 'idealized bodies' aimed at acceptability in society. Body image enhancement is targeted at social acceptance, self-esteem and self-confidence. Inasmuch as images obtained from social media platforms result in body image enhancement with acceptance, self-esteem and self-confidence as the ultimate goals, the possible consequences of body image enhancement are unbearable pain, premature deaths and disfiguration.

It is hence concluded that visuals and texts generated from social media platforms through the means of social interaction precipitate socialization, which in turn induces body enhancement of different forms with the attendant transformations that come with it. This is due mainly to cultural diffusion. This singular act yields improvement in selfesteem and self-confidence as well as social acceptance. Thus, the process of body image enhancement is significantly anchored by cultural transformation, social interaction including social media induced socialization.

\section{Conflict of Interest Statement}

The author declares that the research was conducted in the absence of any commercial or financial relationships that could be construed as a potential conflict of interest. 


\section{References}

Andsager, J. L. (2014). Research directions in social media and body image. Sex Roles, 71(11 -12), 407-413. http://doi.org/10.1007/s11199-014-0430-4.

Bailey, K. A., Gammage, K. L., van Ingen, C., \& Ditor, D. S. (2015). "It's all about acceptance": A qualitative study exploring a model of positive body image for people with spinal cord injury. Body Image, 15, 24-34. http://doi.org/10.1016/j.bodyim.2015.04.010.

Barthes, R. (1977). Rhetoric of the image, in Heath (Ed.). Image, music, text (pp. 32-51), New York: Hill and Wang.

Bowling, A. (2005). Mode of questionnaire administration can have serious effects on data quality. Journal of Public Health, 27(3), 281-291.

Brody, J. E. (2017). Social interaction is critical for mental and physical health. The New York Times.https://www.nytimes.com/2017/06/12/well/live/having-friends-is-good-foryou.html.

Chua, A. (2002). The influence of social interaction on knowledge creation. Journal of Intellectual Capital, 3(4), 375-392, https://doi.org/10.1108/14691930210448297.

Curtis, K., Horton, K., \& Smith, P. (2012). Student nurse socialisation in compassionate practice: A Grounded Theory study. Nurse Education Today, 32, 790-795.

Davis, F. D., Bagozzi, R. P., \& Warshaw, P. R. (1989). User acceptance of computer technology: A comparison of two theoretical models. Management Science, 35, 9821003.

Davison, T. E., \& McCabe, M. P. (2006). Adolescent body image and psychosocial functioning. The Journal of Social Psychology, 146(1), 15-30. http://doi.org/10.3200/SOCP.146.1.15-30.

Dohnt, H. K., \& Tiggemann, M. (2006). Body image concerns in young girls: The role of peers and media prior to adolescence. Journal of Youth \& Adolescence, 35(2), 141-151. http://doi.org/10.1007/s10964-005-9020-7.

Dovie, D.A. (2019a). The status of older adult care in contemporary Ghana: A profile of some emerging issues. Front. Sociol., 4(25), doi:10.3389/fsoc.2019.00025.

Dovie, D.A. (2019b). Assessment of how house ownership shapes health outcomes in urban Ghana. Societies, 9(43), 1-18. doi:10.3390/soc9020043. Special Issue Families, Work and Well-being.

Dovie, D.A. (2018a). Utilization of digital literacy in retirement planning among Ghanaian formal and informal sector workers. Interações, 34, 113-140.

Dovie, D.A. (2018b). Financial literacy in an African society: An essential tool for retirement planning. Contemporary Journal of African Studies, 5, 26-59.

Dovie, D. A. (2017). Preparations of Ghanaian formal and informal sector workers towards retirement. Unpublished doctoral thesis, University of Ghana, Accra.

Dzorgbo, DB.S. (2008). SOCI 201: Basic concepts in Sociology. Accra: Institute of Adult Education. 
Fardouly, J., \& Vartanian, L. R. (2016). Social media and body image concerns: Current research and future directions. Current Opinion in Psychology, 9, 1-5.

Goffman, E. (1981). Forms of talk. Pennsylvania: University of Pennsylvania Press.

Findler, L., Taubman-Ben-Ari, O., \& Jacob, K. (2007). Internal and external contributors to maternal mental health and marital adaptation one year after birth: comparisons of mothers of pre-term and full-term twins. Women \& Health, 46(4), 39-60. http://doi.org/10.1300/J013v46n04.

Hawkins, N., Richards, P. S., Granley, H. Mac, \& Stein, D. M. (2004). The impact of exposure to the thin-ideal media image on women. Eating Disorders, 12(1), 35-50. http://doi.org/10.1080/10640260490267751.

Hochman, N., \& Schwartz, R. (2012). Visualizing instagram: Tracing cultural visual rhythms. In Proceedings of the workshop on Social media visualization (SocMedVis) in Conjunction with the Sixth International AAAI Conference on Weblogs and Social Media (ICWSM-12), Dublin, Ireland, 4-7 June 2012.

Holt, A., \& Lyness, K. P. (2007). Body image and sexual satisfaction: Implications for couple therapy. Journal of Couple \& Relationship Therapy, 6(3), 45-68. http://doi.org/10.1300/J398v06n03.

Hughes, M., \& Kroehler, C. (2005). Sociology: The core. Boston: McGraw Hill.

Huisman, C, \& Kort, H. (2019). Two-Year Use of Care Robot Zora in Dutch Nursing Homes: An Evaluation Study. Healthcare, 7(31), 1-15.

Hummel O'Donnell, N. (2016). Storied lives on Instagram: Factors associated with the need for personal-visual identity. In Proceedings of the Association for Education in Journalism and Mass Communication National Conference, Minneapolis, Minnesota, 47 August 2016.

Hurst, B., Wallace, R., \& Nixon, S. (2013). The impact of social interaction on student learning. Reading Horizons, 52(4), 375-395.

Jackson, D., Firtko, A., \& Edenborough, M., (2007). Personal resilience as a strategy for surviving and thriving in the face of workplace adversity: a literature review. Journal of Advanced Nursing, 60(1), 1-9.

Jodai, H., Zafarghandi, A.M.V, \& Tous, M.D. (2013). Motivation, integrativeness, organizational influence, anxiety, and English achievement. Glottotheory, 4(2). doi:10.1524/glot.2013.0012.

Kadam, P., \& Bhalerao, S. (2010). Sample size calculation. International Journal of Ayurveda Research, 1(1), 55-57.

Kharroub, T., \& Bas, O. (2015). Social media and protests: An examination of Twitter images of the 2011 Egyptian revolution. New Media \& Society, 18, 1973-1992.

Kim, K. B., \& Aubrey, J. S. (2015). A cross-cultural comparison of cognitive and affective mediators in the relationship between media use and body image disturbance: focusing on US and Korean women. Asian Journal of Communication, 25(5), 507-524. http://doi.org/10.1080/01292986.2014.995681. 
Klimova B., Simonova I., Poulova, P., Truhlarova, Z., \& Kuca, K. (2016). Older people and their attitude to the use of information and communication technologies-a review study with special focus on the Czech Republic (older people and their attitude to ICT). Educational Gerontology, 42(5), 361-369.

Lawrie, Z., Sullivan, E. A, Davies, P. S. W., \& Hill, R. J. (2006). Media influence on the body image of children and adolescents. Eating Disorders, 14(5), 355-64. http://doi.org/10.1080/10640260600952506.

Lee, H.-R., Lee, H. E., Choi, J., Kim, J. H., \& Han, H. L. (2014). Social Media Use, Body Image, and Psychological Well-Being: A Cross-Cultural Comparison of Korea and the United States. Journal of Health Communication, 19(12), 1343-1358. http://doi.org/10.1080/10810730.2014.904022.

Leslie, G.R., Larson, R.F., \& Gorman, B.I. (1973). Order and change: Introductory sociology. New York: Oxford University Press.

Macionnis, J. J. (2003). Sociology. Upper Saddle River, NJ: Pearson Prentice Hall.

Monteverde, K. (1995). Applying resource-based strategic analysis: Making the model more accessible. Working paper No. 95-1, Department of Management and Information Systems, St. Joseph's University.

Morin, C., Mercier, A., \& Atlani-Duault, L. (2019). Text-image relationships in tweets: Shaping the meanings of an epidemic. Societies, 9(1); 1-18. doi:10.3390/soc9010012.

Murthy, D., Gross, A., \& McGarry, M. (2016). Visual social media and big data. Interpreting Instagram images posted on Twitter. Digit. Cult. Soc., 2, 113-134.

Murthy, D. (2011). Twitter: Microphone for the masses? Media, Culture \& Society, 33(5), 779-789.

Nahapiet, J., \& Ghoshal, S. (1998). Social capital, intellectual capital and the organizational advantage. The Academy of Management Review, 23(2), 242-266.

Park, N., Park, M., \& Peterson, C. (2010). When is the search for meaning related to life satisfaction? Applied Psychology: Health \& Well-Being, 2(1), 1-13.

Parsons, M., \& Griffiths, R. (2007). The effect of professional socialization on midwives' practice. Women and Birth, 20, 31-34.

Perez, C. (2019). Billionaire diamond trader reportedly dies during penis enlargement procedure. New York Post.

Putnam, R.D. (1995). Bowling alone: America's declining social capital. Journal of Democracy, 6, 65-78.

Quadagno, J. (2014) Ageing and the life course: An introduction to social gerontology $\left(6^{\text {th }}\right.$ ed). McGraw Hill.

Seltzer, E.K., Jean, N.S., Kramer-Golinkoff, E., Asch, D.A., \& Merchant, R.M. (2015). The content of social media's shared images about Ebola: A retrospective study. Public Health, 129, 1273-1277. 
Sharp, G., \& Tiggemann, M. (2016). Educating women about normal female genital $\begin{array}{lllll}\text { appearance } \quad \text { variation. } & \text { Bmage, } & \text { 70 }\end{array}$ http://doi.org/10.1016/j.bodyim.2015.11.006.

Sharifi, S.M., Omidi, A., \& Marzban (2016). The Impact of Instagram Use on Body Image Concerns among Iranian University Female Students: A Phenomenological Approach. International Journal of Academic Research in Psychology, 3(1), 26-36. DOI: 10.6007/IJARP/v3-i1/2280.

Sulliman, N.N. (2019). The intertwined relationship between power and patriarchy: Examples from resource extractive industries. Societies, 9(14), 1-11. Doi:10.3390/soc9010014 www.mdpi.com/journal/societies.

Swami, V., \& Knowles, V. (2014). Mental health literacy of negative body image: symptom recognition and beliefs about body image in a British community sample. International Journal of Culture and Mental Health, 7(2), 199-215. http://doi.org/10.1080/17542863.2013.769611.

Terpstra, T., Stronkman, R., de Vries, A., \& Paradies, G.L. (2012). Towards a realtime Twitter analysis during crises for operational crisis management. In Proceedings of the 9th International ISCRAM Conference, Vancouver, BC, Canada, 22-25 April 2012.

Tifentale, A., \& Manovich, L. (2015). Selfiecity: Exploring photography and selffashioning in social media, in Berry, D., Dieter, M., Eds., Postdigital Aesthetics (pp. 109122), Palgrave Macmillan: Basingstoke, UK.

Vis, F., Faulkner, S., Parry, K., Manuykhina, Y., \& Evans, L. (2013). Twitpic-ing the riots: Analysing images shared on Twitter during the 2011 UK riots, in Weller, Bruns, Burgess, Mahrt, \& Puschmann (Eds.). Twitter and Society (pp. 385-398), New York: Peter Lang.

Vogel, E.A., Rose, J.P., Roberts, L.R. \& Eckles, K. (2014). Social comparison, social media and self-esteem. Psychology of Popular Media Culture, 3(4), 206-222.

Wagenbach, P. (2004). Lesbian body image and eating issues. Journal of Psychology \& Human Sexuality, 15(4), 205-227.

Walsh, M.J., \& Baker, S.A. (2017). The selfie and the transformation of the public-private distinction. Information, Communication \& Society, 20(8), 1185-1203.

Yan, T., Ryan, L., Becker, S.E., \& Smith, J. (2015). Assessing quality of answers to a global subjective well-being question through response times. Survey Research Methods, 9(2), 101-109.

Zappavigna, M. (2016). Social media photography: Construing subjectivity in Instagram images. Visual Communication, 15(3), 271-292.

Zhang, M. (2012). A Chinese beauty story: how college women in China negotiate beauty, body image, and mass media. Chinese Journal of Communication, 5(4), 437454. http://doi.org/10.1080/17544750.2012.723387. 
Delali Adjoa Dovie has $\mathrm{PhD}$ in the Sociology from the University of Ghana. Her current research interests include: retirement planning, informal sector work dynamics, labour issues, digital literacy and generational articulations, ageing and development, ageing and anti-ageing products, elder welfare, social needs and care, development of formal support infrastructure for older people, the elderly and housing, population ageing, active ageing, educational transformations.

凶dellsellad@gmail.com 